\title{
Surveillance of occupational lung diseases in Canada
}

\author{
HELEN Dimich-WARD PhD, GUSTAVo R CONTRERAS MD, ROXANNE ROUSSEAU BSc, \\ MOIRA CHAN-YEUNG MD FRCP \\ Occupational Lung Diseases Research Unit, Respiratory Division, Department of Medicine, \\ University of British Columbia, Vancouver, British Columbia
}

H Dimich-Ward, GR Contreras, R Rousseau, M CHAN-YEUNG. Surveillance of occupational lung diseases in Canada. Can Respir J 1996;3(5):291-294.

Surveillance programs for occupational lung diseases are reviewed, with reference to a two-year pilot study that was undertaken in the province of British Columbia. Members of the British Columbia Thoracic Society were invited to participate by reporting any new cases of occupational lung disease in each two-month period. Participating physicians responded well during the first year of the pilot study, but longer term commitment was difficult to maintain. It is recommend that physicians be educated, starting in medical school, about the recognition and diagnosis of occupational diseases and the importance of surveillance of chronic diseases. The authors encourage, at least on a trial basis, a nationally based surveillance program of occupational lung diseases.

Key Words: Lung diseases, Occupational diseases, Surveillance

\section{Surveillance des pneumopathies professionnelles au Canada}

RÉSUMÉ : Les programmes de surveillance des pneumopathies professionnelles sont passés en revue, suite à une étude pilote de deux ans qui a été menée en ColombieBritannique. Les membres de la Société de thoracologie de la Colombie-Britannique ont été invités à participer à cette étude en rapportant tous les nouveaux cas de pneumopathies professionnelles tous les deux mois. Les médecins participants ont bien rapporté les données pendant la première année de l'étude pilote, mais leur contribution a été difficile à maintenir à plus long terme. On recommande que, dès le début de leurs études de médecine, les médecins apprennent à reconnaître et à diagnostiquer les pneumopathies professionnelles, et à apprécier l'importance de la surveillance des maladies chroniques. Les auteurs encouragent, au moins à titre d'essai, un programme de surveillance des maladies professionnelles d'envergure nationale.
$\mathrm{S}_{\mathrm{s}}^{\mathrm{u}}$ urveillance of disease usually refers to the "ongoing scrutiny of all aspects of occurrence and spread of a disease that are pertinent to effective control" (1). The primary goal of a surveillance program of occupational diseases is to monitor trends or patterns of a health event or of risk factors, with the aim of implementing and assessing the efficacy of interventions.

Currently there is no comprehensive surveillance program

Correspondence: Dr Helen Dimich-Ward, Respiratory Division, Department of Medicine, University of British Columbia, 2775 Heather Street, Vancouver, British Columbia V5Z 3J5. Telephone 604-875-5548, fax 604-875-4695, e-mail hward@unixg.ubc.ca 


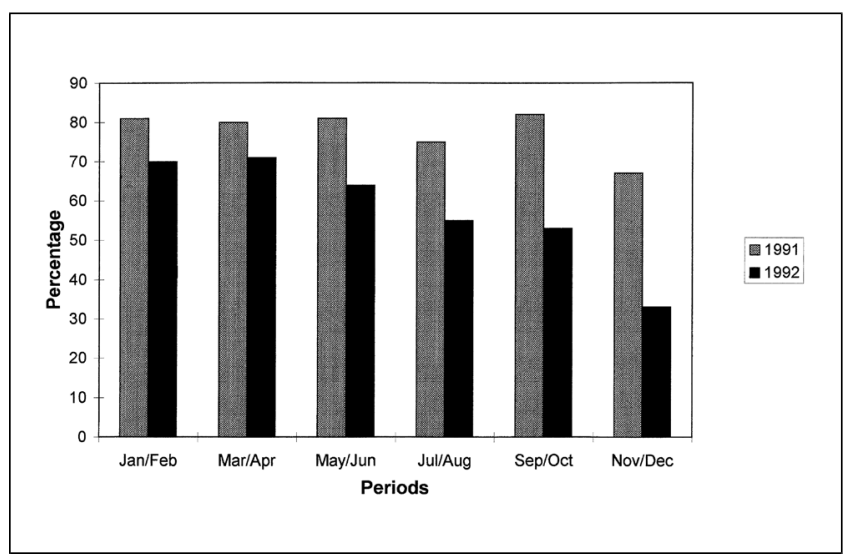

Figure 1) Percentage of participating physicians who returned cards in each of the two-month study periods during 1991 and 1992

of occupational diseases in Canada. Spiegel and Yassi (2) gave an excellent review on the potential usefulness of various Canadian data sources, such as health insurances claims, hospital separation forms, and provincial and national health registries, for the surveillance of occupational disease. An alternative data source is information on diseases, injuries and deaths that are routinely collected by the provincial workers' compensation boards (WCB). WCB data are comprehensive for the working population and require strict diagnostic criteria for acceptance. However, there is a lack of standardization, and the data are incomplete because they are based on 'accepted claims' in which early indications of disease are not recognized; there is also a hesitancy by potential claimants and physicians to become involved in the bureaucracy.

Reporting by physicians or other health care providers can provide a valuable method for surveillance of occupational diseases. An advantage to using physicians' reports is that they are generally available in a more timely way than registry data, which is particularly important when case reports are used to direct intervention efforts in individual cases. By establishing a system for reporting specified diseases, physicians can be a resource for reporting unusual cases or clusters that may be of public health concern. At present there is no such system in Canada for the reporting of occupational lung diseases.

To assess the feasibility of establishing an occupational lung diseases registry, a pilot study was conducted in British Columbia based on voluntary reporting by physicians.

\section{PILOT OCCUPATIONAL LUNG DISEASES REGISTRY IN BRITISH COLUMBIA}

The pilot study was conducted between 1991 and 1992 using a method similar to that used by the Surveillance of Work Related Occupational Respiratory Disease (SWORD) project (3), with some modifications. Details of the first year of this pilot study have been reported previously (4). All participants were members of the British Columbia Thoracic Society and included respirologists and a number of general practitioners and internal medicine physicians with interest in respiratory diseases, located in different regions of British

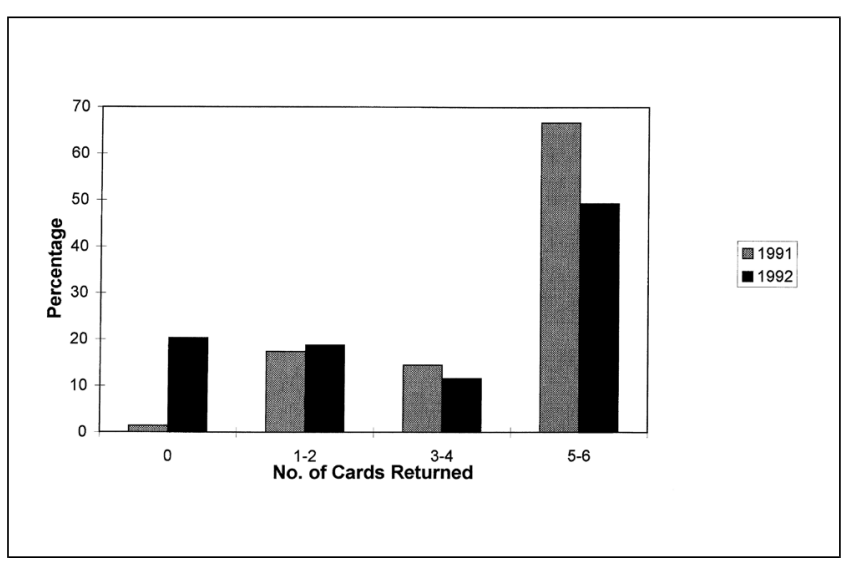

Figure 2) Percentage of total reporting physicians who returned cards (grouped as 0, 1-2, 3-4, 5-6 cards) per year

Columbia. The population in the local health areas served by the participating physicians represented $81.5 \%$ of the total labour force in British Columbia. The 68 participants were asked to report, every two months, new cases of respiratory illness that they believed to be attributed to work exposure. At the end of two months they were asked to return the cards and they received new ones for the next period. The importance of returning all cards, even with no case report, was emphasized. Physicians who did not return the card at the end of the reporting period were contacted by letter or by telephone. To avoid duplication of reports, the patient's surname and first initial, sex, age, city or town of residence, job, type of industry where he or she was working and the suspected agent provoking the disease were also recorded. The reporting card had a diagnostic classification of the most frequently encountered occupational lung diseases. A brief report of the previous reporting period was distributed to the participating physicians together with the new cards.

As shown in Figure 1, during the first half of the first year of this project, the rate of return of reporting cards was $80 \%$. By the end of the first year the number decreased to $67 \%$; at the end of the second year the rate was only $33 \%$. During the first year, $66.7 \%$ of the participating physicians returned five to six cards, and $1.4 \%$ did not return any cards. During the second year, the corresponding figures were $49.3 \%$ and $20.3 \%$, respectively (Figure 2).

In 1991, 246 new cases of occupational lung diseases were reported by the participating physicians. In the same year, the WCB of British Columbia accepted 319 claims for occupational lung disease. The discrepancy is related to differences in the population covered and of diagnosis and reporting criteria. In the registry, the largest diagnostic group was occupational asthma, accounting for $50 \%$ of all reported cases, followed by asbestos-related diseases $(32 \%)$, chronic obstructive pulmonary diseases $(4.5 \%)$ and lung cancer (2.8\%). Physicians reported 40 cases of mesothelioma in 1991 but none was reported by the WCB of British Columbia. One hundred and twenty-four cases of work-related asthma were reported to the registry, while the WCB accepted only 43 such new cases. Conversely, only three cases 
of inhalation accidents were reported by physicians to the registry while 208 cases were accepted by the WCB. In British Columbia, most inhalation accidents are reported directly to the WCB by workers, and the claims are usually accepted without a medical certificate.

Our pilot study showed that the registry was successful during the first year, as demonstrated by the rate of return of reporting cards. The incidence of occupational lung diseases of 181 per million reported during the first year was twice that reported by the SWORD project in the United Kingdom (3). However, two-thirds of the physicians failed to file records at the end of two years; interest in the project was difficult to maintain, especially for physicians who had not encountered a case of occupational lung disease during the study period.

\section{OCCUPATIONAL LUNG DISEASES SURVEILLANCE}

The pilot project was based on the strategies used by the SWORD project initiated in the United Kingdom in 1989 (3). Members of the British Thoracic Society and the Society of Occupational Medicine were asked to report to the project any newly diagnosed respiratory illness that they believed was due to occupational or work-related exposure, and all participants received monthly feedback. Occupational asthma was found to be the most commonly reported occupational lung disease. The results of the project were compared with data concerning those who received disablement benefits. The figures from the two sources were similar for asbestosis, lung cancer and byssinosis, but the figure for occupational asthma (554 cases) contrasted to the official figure of 222 cases based only on agents for which disability benefits are payable. It was suggested that the true frequency of acute occupational respiratory diseases might be three times greater than has been reported throughout traditional sources such as the use of workers' compensation and employers' records. While the rate of participation of invited chest physicians in the SWORD project during the first year was $83 \%$, the rate of return of the reporting cards by physicians during the following years has not been reported (5).

The United States National Institute for Occupational Safety and Health (NIOSH) has established the Sentinel Event Notification System for Occupational Risks (SENSOR) program as a model surveillance program based on health provider recognition and notification (6). The SENSOR program has four components: a set of selected target conditions; a network of sentinel health care providers; a surveillance centre that receives and analyzes reports; and work site intervention activity that is guided by surveillance data. A sentinel occupational health event most suited to health care provider reporting and intervention is occupational asthma. However, underreporting is a persistent problem, with the low rate of physician participation being cited as one of the most important limiting factors in the project. California has established a statewide surveillance of occupational asthma (7) using the 'Doctor's first report of occupational injury of illness', which are filed with private, state-run and self-insured workers' compensation insurance carriers. In the first year of the study, there were 330 reports of physiciandiagnosed asthma. Of those cases investigated further, $27 \%$ had work-aggravated asthma, while $47 \%$ were suspected of having occupational asthma.

In the United States, a survey conducted in 1985 (8) showed that 32 states had programs for reporting occupational illnesses by one or more sources. In 16 states, legal penalties existed for nonreporting. Despite this, underreporting by physicians in these states was common. Reasons for the failure of reporting by physicians included the following: lack of guidance as to what conditions to report or what criteria should be used for reporting occupational lung diseases; lack of training to recognize occupational diseases and a perception that occupational disease reporting is useless compared with reporting infectious disease; and reluctance to become involved with the WCBs or with litigation. Regulation-enforced reporting has been successfully demonstrated in Finland (9). For over 30 years, the Institute of Occupational Health in Finland has had a register of occupational diseases in which physicians are required by law to report every case of occupational disease or disease related to work. Data are received from three sources: reports of occupational disease filed by provincial medical officers; accident reports and diagnoses submitted by insurance companies; and cases diagnosed at the Institute of Occupational Health. A comparison of 1989 returns showed that the reported incidence of occupational asthma in Finland was six times higher than that in the United Kingdom.

\section{DISCUSSION}

Participating physicians were encouraged to report cases that they thought were most likely to be due to occupational exposure. Comparison between the pilot registry study and the data from the WCB showed little discrepancy in the incidence of asbestosis and silicosis, but considerable discrepancy in the incidence of occupational asthma. Not only is the diagnosis of occupational asthma less well understood, many physicians do not have the facilities to confirm the diagnosis by objective means.

In general, the case definitions used for compensation purposes are stricter, while the case definitions for surveillance programs may be less specific but more sensitive if the purpose of the surveillance program is to trigger a more detailed investigation. Therefore, it is important to define the purpose of the surveillance program if a registry is to be set up.

Can an occupational lung disease surveillance program be mounted successfully in Canada? A volunteer-based surveillance program is vulnerable to underreporting and eventual drop-out. Under such a system, a one-time 'snapshot' of the national incidence of occupational lung disease is possible. Longer term secular trends would be much more difficult to establish. Even with a national regulation-enforced system, underreporting could still be a problem. The key to establishing a successful registry lies in the better education of physicians, starting in medical schools, on the recognition and 
diagnosis of occupational diseases as well as the importance of reporting to appropriate agencies for preventive measures. Communication of research to practising physicians is an important part of the process. For example, there is increasing evidence of an association between chronic obstructive pulmonary disease and exposure to many different types of inorganic and organic dusts, beyond any effect due to smoking (10).

A volunteer-based national occupational lung diseases program coordinated by a network of academic centres could provide valuable information on trends in disease and improve upon the possibilities of early detection to allow for in- tervention. An additional benefit of a national surveillance program would be the expanded awareness and educational opportunities for the health care community regarding the nature and impact of occupational lung diseases.

ACKNOWLEDGEMENTS: This work was supported by the British Columbia Lung Association and the Workers' Compensation Board of British Columbia. The authors thank all physicians who participated in the registry for their dedication and patience in submitting the reporting cards regularly, and Dr JC McDonald for his advice in setting up the registry.

\section{REFERENCES}

1. Nicholls CL, Ho KK, Foster LT. Local health area statistical profiles for British Columbia. Victoria: Ministry of Health and Ministry Responsible for Seniors, 1992.

2. Spiegel J, Yassi A. Occupational diseases surveillance in Canada: a framework for considering options and opportunities. Can J Public Health 1991;82:294-9.

3. Meredith S, Taylor V, McDonald J. Occupational respiratory disease in the United Kingdom 1989: a report to the British Thoracic Society and the Society of Occupational Medicine by the SWORD project group. Br J Ind Med 1991;48:292-8.

4. Contreras G, Rousseau R, Chan-Yeung M. Short report: occupational respiratory diseases in British Columbia, Canada. Occup Environ Med 1994;51:710-2.

5. Meredith S. Reported incidence of occupational asthma in the United Kingdom, 1989-90. J Epidemiol Community Health 1993;47:459-63.

6. Levy B, Johnson A, Rest K, Wegman D, Sencer D. Evaluation of the sentinel event notification system for occupational risks (SENSOR). New York: NIOSH, 1992.

7. Harrison, RJ, Reinisch F, Cussler S, Osorio AM. Surveillance of occupational asthma in California: application of the NIOSH case definition. Am J Respir Crit Care Med 1995;151:A418. (Abst)

8. Freund E, Seligman PJ, Chorba TL, Satford SK, Drachman JG, Hull HF. Mandatory reporting of occupational diseases by clinicians. JAMA 1989;262:3041-4.

9. Keskinen H. Registers for occupational diseases. BMJ 1991;303:597-8.

10. Dimich-Ward H, Kennedy SM, Chan-Yeung M. Occupational exposure and chronic airflow limitation. Can Respir J 1996;3:133-40. 


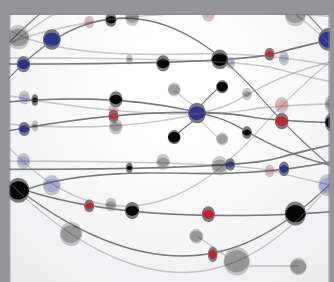

The Scientific World Journal
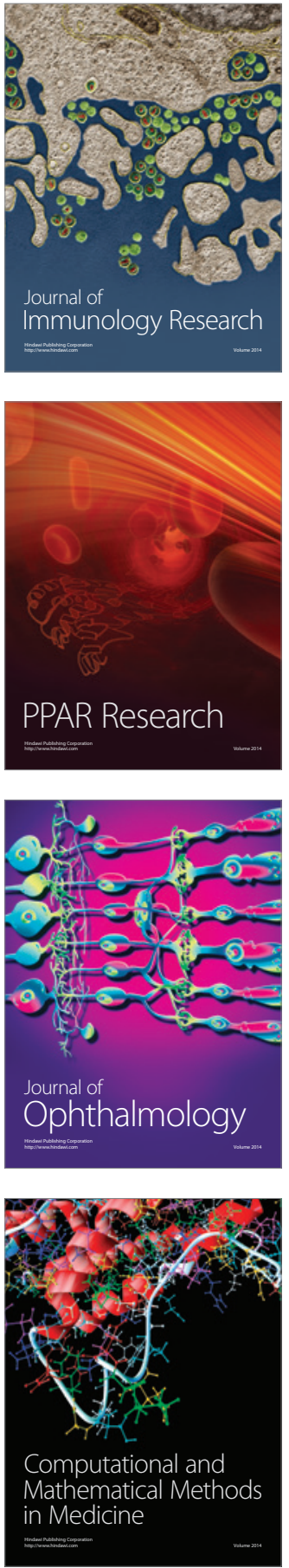

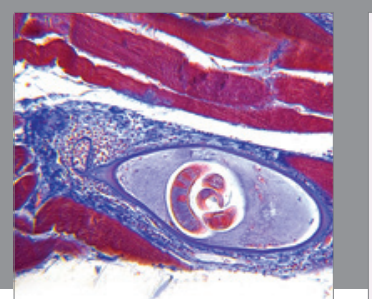

Gastroenterology Research and Practice

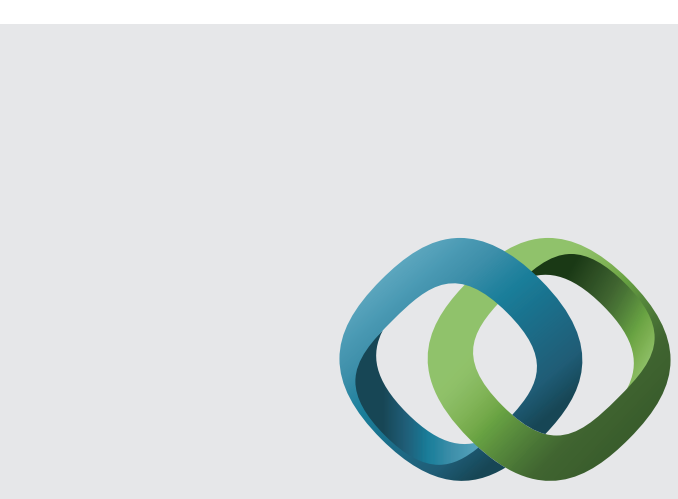

\section{Hindawi}

Submit your manuscripts at

http://www.hindawi.com
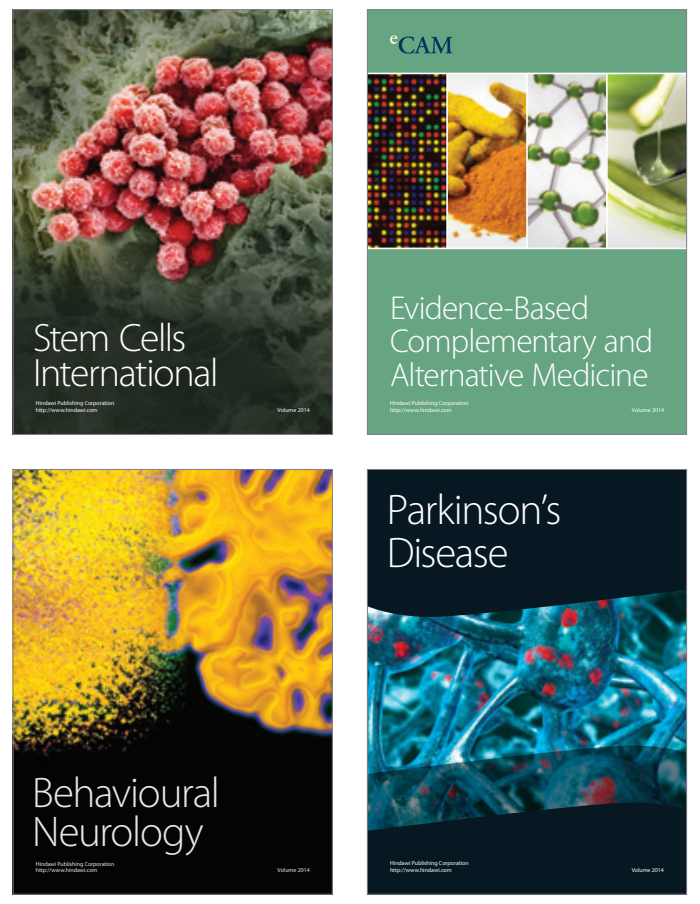
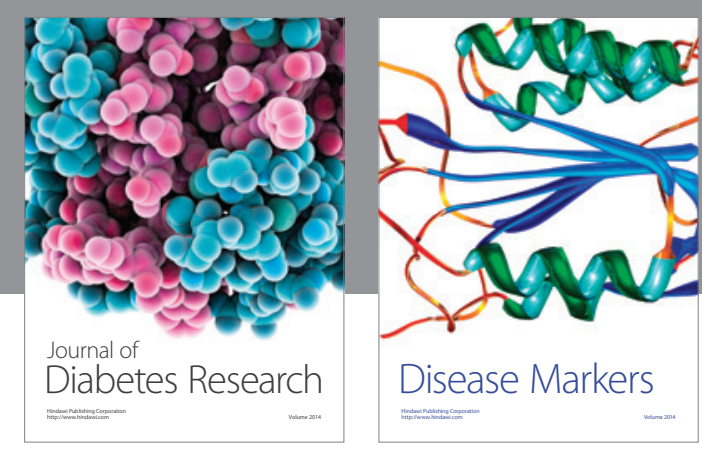

Disease Markers
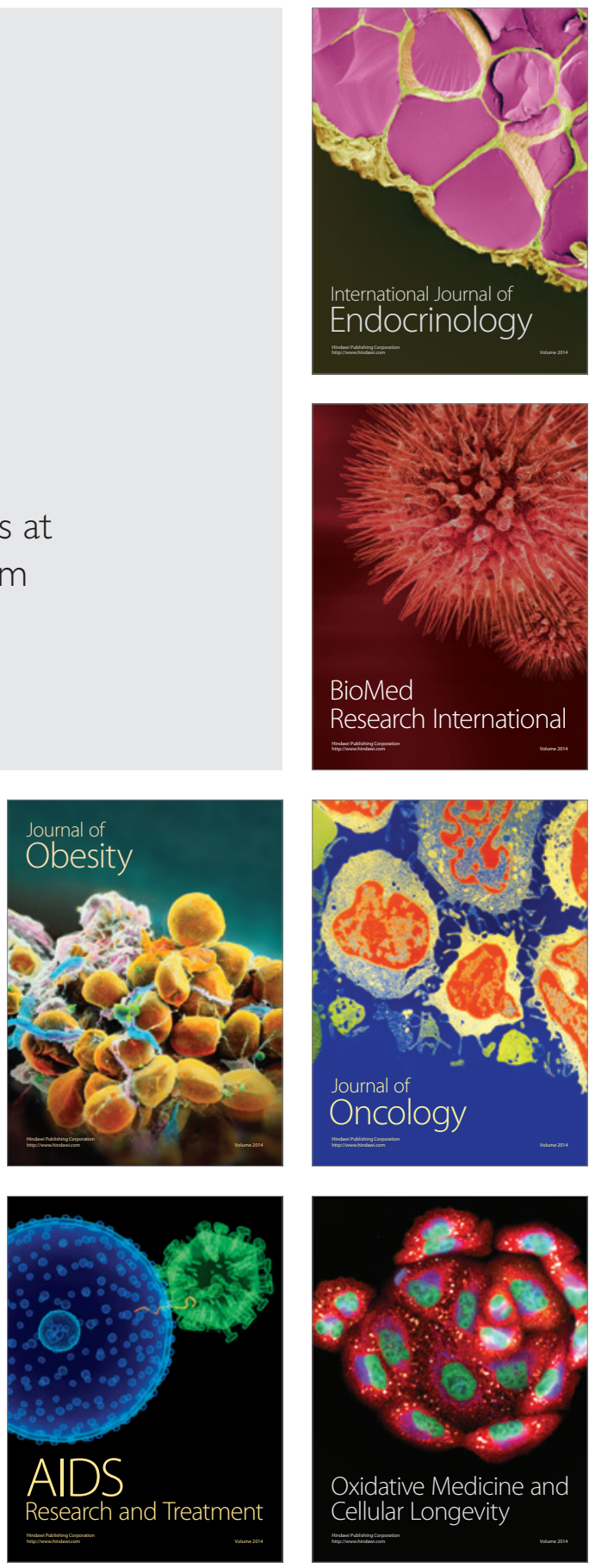